\title{
The Practices of Making Innovation Public
}

\begin{abstract}
A Commentary on Taylor Dotson's “Technological Determinism and Permissionless Innovation as Technocratic Governing Mentalities: Psychocultural Barriers to the Democratization of Technology"
\end{abstract}

\author{
SUJATHA RAMAN ${ }^{1}$ \\ University of Nottingham
}

\section{Keywords}

permissionless innovation; responsible innovation; STS; democracy

\section{Introduction}

Taylor Dotson rightly draws attention to the problems of deterministic and breathless invocations of the ability of technological innovation to set us free and create the good life. He suggests that STS research can and should be used for practical effect, and that we ought to devote more effort to transforming the status quo of market-led innovation proceeding without a substantive democratic mandate. I agree. But having witnessed the emergence over the past decade or more of a movement engaged in precisely the activity of "doing" STS, I am perplexed by Dotson's argument that we are still too preoccupied with the minor task of excising technological determinism from academic thinking-as opposed to grappling with the normative power of determinism as an enduring force in the world.

Dotson also offers a remedy for the persistence of what he characterizes as technocratic governing mentalities. According to Dotson (2015), STS first needs to acknowledge that a major barrier to democratization is psychocultural in nature. Why do people still lap up the latest smartphone upgrade and drive big cars? It is because they experience technology as enhancing freedom, thus rendering democratization unnecessary. This situation, he suggests, can be transformed by building counter-narratives informed by social psychology research to steer people towards alternative beliefs more conducive to democratic innovation. Again, while I endorse the need for counter-narratives, I am less convinced that these should be targeted at "beliefs" and "minds" of citizens. Writing on climate change, Shove (2010) has set out the limitations of an "ABC" (attitudes/behaviour/choice) model of action, arguing instead that energy use is rooted in habits, social practices and infrastructural networks that gain their enduring power over time. Translating that insight to democratic innovation, I argue that we need to engage with and

\footnotetext{
Sujatha Raman, Email: Sujatha.raman@nottingham.ac.uk

Copyright (c) 2015 (Sujatha Raman). Licensed under the Creative Commons Attribution Non-commercial No Derivatives (by-nc-nd). Available at estsjournal.org.
} 
allow our narratives to be affected by the complexities of social practices where democratization ultimately happens.

In what follows, I draw on my experience as deputy director of a research program funded by the UK Leverhulme Trust, Making Science Public, to offer some reflections on the challenges set out by Dotson. This program is formally charged with the task of investigating democratization rather than "doing" it, though, in practice, these boundaries are blurred, allowing us to reflect on lessons from our practical interventions conducted within other research (for example, as social scientists embedded in science/engineering projects) and teaching (for example, introducing STS ideas to science or engineering students) activities.

The phrase, "making science public," draws attention to the significance of democratization as an activity as opposed to a theoretical construct alone. Democratic innovation has to be made (as Dotson also implies), but making requires us to work with and across multiple materials, sites and institutions. This multiplicity in turn means that it is misleading and self-defeating to work from a model of opposition between dominant innovation and a passive/accepting public, and to focus on parsimonious narratives for countering libertarian excess. Yes, to be compelling, any single political argument will require some reduction of complexity. But if democratization and argumentation are activities, we must pay attention to the work of developing narratives in concrete contexts where the beliefs, experiences and values we are engaging with will necessarily vary. Sometimes these will talk back and transform the narratives we have to offer. This means we cannot escape plurality and complexity, but rather than seeing these as constraints, I suggest that new narratives will emerge from and in conjunction with democratic experiments rather than as a substitute for them.

\section{Multiple Sites of Practice}

STS contributions to the democratization of innovation extend well beyond charting desired end-states as Dotson implies. They revolve around, for example, responsible innovation (Stilgoe et al. 2013); the social licence of research and industry to operate (see the special issue of Social Epistemology, vol. 28 (3-4), "Social License to Operate"); laboratory-based interventions (Schuurbiers and Fisher 2009); critical engagements with technoscientific policy regimes (Wilsdon et al. 2005); and public dialogues around science and technology (Pallett 2015). They range from entire volumes (e.g., Owen et al. 2013) to policy papers (several reports in the 2000s published by the former science policy team in the think-tank, Demos) to 140-character tweets and blogging (e.g., the Political Science blog on the Guardian). These conversations straddle Europe and North America; increasingly, they also reach into global South contexts to consider the limits of conventional narratives of innovation for "development" (Macnaghten et al. 2014) and to call attention to situations in which innovation in the global North depends on resources extracted in the South yet bears little responsibility for negative impacts (Raman and Mohr 2014).

Some of this work may be published in academic journals, but most of it emerges from experiments to engage with the status quo through embedding STS in scientific, policy and public sites. This multiplicity of sites is important because it suggests that technocratic governing mentalities, to use Dotson's phrase, cannot be transformed only by targeting the public with a set of messages-it requires going deep into institutions, research projects and 
public forums, sometimes working collaboratively with people from outside STS and building relationships that allow us to open up the innovation system. Recent incarnations of this kind of STS work are tinged with self-criticism of the limitations and failures in terms of what has been achieved so far and the need to "recommit to studying and articulating a more ambitious project of publicly engaged science" (Stilgoe et al. 2014, 11). Others argue for understanding recent activities as part of a long game of building the capacity to democratize governance of research and innovation across different levels (Guston 2014). But what they have in common is a preoccupation with developing/improving the languages, methods and practices for stimulating a rethinking of default positions in research and innovation in realworld settings. Battles over some abstraction called "technological determinism" seem a distant memory.

\section{Multiple Publics}

I suspect that Dotson might argue that none of this activity is making any difference on the ground. Innovation trajectories carry on largely unfettered by such democratic exercises. But surely the answer then is to deepen, extend and further innovate these experiments. Instead, Dotson puts his faith in psychology experiments purporting to show that people can change their beliefs once information is framed in the right way, hence his call for "parsimonious counter-narratives" to the dominant narrative of autonomous technological innovation that requires no authorization other than that of the market. If I'm reading him correctly, Dotson paradoxically seeks an answer to the absence of democratic involvement in innovation not so much in democracy but in a marketplace of ideas where progressives might out-perform libertarians in the competition for public attention.

By contrast, recent STS work on democratization is mostly addressed to state and scientific policy institutions, calling for more recognition of plural public perspectives and visions of what innovation might look like (e.g., Stirling 2015). This is more than just a theoretical model, however, as it emerges from a history of the kinds of engagements I have outlined-theory and practice can and do inform each other. It is predicated on the following assumptions that might also serve as warnings as we look to the future.

First, how we imagine and engage with the public is important. Going into the process assuming that we already know what the public believes does not bode well for democracy. When Dotson claims that the public experience technology as liberatory, I want to ask: how does he know? Certainly reading this from my location in Europe, the claim sits oddly with the debates we have been having on relations between technoscience and society as being in "crisis." Policymakers are preoccupied with high-profile public opposition, resistance and protests around specific technological developments, notably in the life sciences. For them, the major worry is to secure public acceptance of innovation. But this point is not just about expecting our discourses to reflect the truths that we have discovered, in this case, a truth about variation in public beliefs. It is also an eminently practical one-our knowledge of the other's beliefs (including which ones are deep-rooted and which are less so) is a relational thing. It is acquired and negotiated in interaction with other people, a process that is necessarily hazardous as people can "talk back" in unexpected ways. This does not mean we can't make general claims in public, but we should do it in a way that invites a 
response or that is discussable-otherwise, we are simply reduced to talking past each other from our respective ideological accounts (Williams 2015).

Second, there is sensitivity to complexity in STS work on democratization because of an awareness that narratives countering the status quo can also gloss over power relationships and uncomfortable realities. For example, a dominant fault-line in climate change discussions today is between fossil fuel divestment and investment in renewable energy. The case for divestment is a powerful one, but it derives part of its authority and plausibility from the appeal to renewables as an alternative future. From an STS perspective, a renewable energy transition in the light of climate change is important, but a habit of cultivating attention to complexity means that we should watch out for unexamined challenges such as the hazards affecting people in the vicinity of sites where the materials required to make turbines or photovoltaic panels are mined or disposed of (Raman 2013). These issues can be brought under the umbrella of a renewable transition and discussed, but a simple fossil-fuel-versus-renewables structuring of the debate has impeded this possibility.

In conclusion I will briefly consider one of my own attempts to develop a counternarrative of sorts to Big Innovation. Drawing from social psychology, Dotson suggests that counter-narratives will need to be framed as extensions of, rather than radical departures from, status quo values. In this vein, I have recently tried to articulate how responsible innovation is primarily about promoting innovation (a much valorized quality) rather than constraining it. Normally, STS accounts of responsible innovation are framed in terms of a concern with potential losses to social and natural worlds brought about by transformative technologies (e.g., synthetic biology, nanotechnology, geoengineering, etc.). Here, responsible innovation appears to be about pausing or slowing down a disruptive process of change sought by technological innovation. But what if we were to think about it as intrinsically about innovating in social, economic and industrial systems in conjunction with the technical (Raman 2014; Raman 2015)? Looked at this way, it is the dominant pathway of innovation that appears paradoxically slow in its entrenchment in established market-based models, while the logic of responsible innovation displays an impatience for transforming society in the here and the now through alternative novel visions (for example, by building humanscale energy systems or addressing social inequalities).

To carry such a narrative forward and democratize it, however, requires experimenting with it in multiple conversations and sites of engagement. The test of a counter-narrative is in these spaces of engagement and modes of response or non-response. It would mean paying attention to contradictions and dilemmas in say, building human-scale systems or attempting to root out inequality-who wants them? who will get to have a say? who will decide? how would change be pushed through and at whose expense? I am doubtful that a psychocultural approach will be of assistance in this regard, but I applaud Dotson's effort to look beyond our usual resources to develop his vision of taking the democratization of innovation agenda forward.

\section{Acknowledgement}

This work is aligned with the Leverhulme Making Science Public Programme (RP2011-SP013). Thanks also to pioneering work undertaken at Arizona State University where I was hosted as Visiting Scholar in 2014-15. 


\section{References}

Dotson, T. 2015. “Technological Determinism and Permissionless Innovation as Technocratic Governing Mentalities: Psychocultural Barriers to the Democratization of Technology." Engaging Science, Technology, and Society 1: 98-120. DOI: http://dx.doi.org/10.17351/ests2015.009.

Guston, D. 2014. “Understanding 'Anticipatory Governance."” Social Studies of Science 44 (2):218-42. doi:10.1177/0306312713508669

P. Macnaghten, R. Owen, J. Stilgoe, B. Wynne, A. Azevedo, A. de Campos, J. Chilvers, R. Dagnino, G. di Giulio, E. Frow, B. Garvey, C. Groves, S. Hartley, M. Knobel, E. Kobayashi, M. Lehtonen, J. Lezaun, L. Mello, M. Monteiro, J. Pamplona da Costa, C. Rigolin, B. Rondani, M. Staykova, R. Taddei, C. Till, D. Tyfield, S. Wilford \& L. Velho. 2014. "Responsible innovation across borders: tensions, paradoxes and possibilities." Journal of Responsible Innovation 1 (2):191-199, DOI: 10.1080/23299460.2014.922249

Owen, R., J. Stilgoe, P. Macnaghten, M. Gorman, E. Fisher and D. Guston. 2013. "A Framework for Responsible Innovation." In Responsible Innovation, edited by R.Owen, J. Bessant and M. Heintz, 27-50. Chichester, England: John Wiley and Sons.

Pallett, H. 2015. "Public Participation Organizations and Open Policy A Constitutional Moment for British Democracy?" Science Communication 37 (6):769-794.

Raman, S. 2013. Fossilizing Renewable Energies. Science as Culture 22 (2):172-180.

Raman, S., and Mohr, A. 2014. "Biofuels and the role of space in sustainable innovation journeys." Journal of cleaner production 65:224-233.

Raman, S. 2014. Responsive Research: Putting the Innovative back into Agendas for Innovation. Paper for Sciencewise-ERC, UK, with contributions from M. Clifford, S. de Saille, D. Gent, S. Hartley, A. Mohr and T. Sesan. http://www.sciencewiseerc.org.uk/cms/assets/Uploads/Responsive-ResearchFINAL-VERSION.pdf.

Raman, S. 2015. “Responsive novelty: taking innovation seriously in societal research agendas for synthetic biology." Journal of Responsible Innovation 2 (1):117-120.

Schuurbiers, D., and Fisher, E. 2009. “Lab-scale intervention.” EMBO reports 10 (5): 424-427.

Shove, E. 2010. Beyond the ABC: climate change policy and theories of social change. Environment and planning. A 42 (6):1273-1285.

Stilgoe, J., Owen, R., and Macnaghten, P. 2013. “Developing a framework for responsible innovation." Research Policy 42 (9):1568-1580.

Stilgoe, J., Lock, S. J., and Wilsdon, J. 2014. "Why should we promote public engagement with science?" Public Understanding of Science 23 (1):4-15.

Stirling, A. 2015. "From Knowledge Economy to Innovation Democracy." ESRC STEPS Working Paper http:/ / steps-centre.org/2015/blog/stirlinginnovdemo/

Williams, R. 2015. "What Orwell can teach us about the language of terror and war." Edited extract of the 2015 Orwell lecture, available at http:/ / www.theguardian.com/books/2015/dec/12/words-on-war-a-summons-towriters-orwell-lecture

Wilsdon, J., B. Wynne and J. Stilgoe. 2005. The public value of science. London: Demos. 